\title{
The Ce and $\mathrm{Nd}$ isotope inventory of lunar basalts - implications for the bulk Moon composition
}

\author{
ERIC HASENSTAB ${ }^{1}$, MAXWELL MARZBAN THIEMENS ${ }^{2}$, \\ ERIK STRUB ${ }^{3}$, PETER SPRUNG ${ }^{4}$ AND CARSTEN \\ MÜNKER $^{1}$ \\ ${ }^{1}$ Institut für Geologie und Mineralogie \\ ${ }^{2}$ Université Libre de Bruxelles \\ ${ }^{3}$ Abteilung Nuklearchemie \\ ${ }^{4}$ Paul Scherrer Institut \\ Presenting Author: ehasens1@uni-koeln.de
}

The bulk composition of the Moon provides critical constraints on its building blocks. Recent analyses of ${ }^{142} \mathrm{Nd} /{ }^{144} \mathrm{Nd}$ isotope compositions of rocks from the Earth and the Moon have provided divergent interpretations in the past ${ }^{[1]}$, and it remains ambiguous whether or not the Moon is chondritic in its composition. Due to the strongly coupled behavior of the light rare earth elements during geochemical processes, the long-lived ${ }^{138} \mathrm{La}^{138} \mathrm{Ce}$ decay system is an excellent tool to complement ${ }^{147} \mathrm{Sm}-{ }^{143} \mathrm{Nd}$ and ${ }^{146} \mathrm{Sm}-{ }^{142} \mathrm{Nd}$ isotope systematics, as it can provide new, independent insights into the bulk composition of the Moon. For this purpose, we investigated the combined ${ }^{138} \mathrm{La}^{-}{ }^{138} \mathrm{Ce}$ and ${ }^{147} \mathrm{Sm}-{ }^{143} \mathrm{Nd}$ isotope inventory of 30 lunar rocks from various petrological rock types, including depleted to enriched lithologies (low $\mathrm{Ti}$ basalts, high $\mathrm{Ti}$ basalts and KREEPs) as well as crustal rocks (ferroan anorthosites). Our Ce$\mathrm{Nd}$ isotope array obtained for lunar rocks does not intersect the chondritic value, implying that the bulk Moon is slightly but resolvably non-chondritic. To better characterize the nonchondritic bulk composition of the Moon, we conducted trace element modelling for lunar magma ocean crystallization, following the crystallization sequence after ref. ${ }^{[2]}$. The best fit for our data is observed, if a slightly depleted composition for the bulk Moon is assumed. The origin of the depleted character of the Moon remains a matter of debate, although it seems most likely that it was inherited from Earth during the giant impact. This could have been achieved if (1) the accessible proto-Earth was depleted itself ${ }^{[3]}$ or (2) if the proto-Earth had a layered mantle, possibly the product of an early magma ocean ${ }^{[4]}$.

[1] Brandon et al., (2009) GCA, 73, 6421-6445. [2] Snyder et al., (1992) GCA, 56, 3809-3823. [3] O'Neill and Palme (2008) Phil. Tans. R. Soc. A, 366, 4205-4238. [4] Corgne and Wood (2005) GCA, 69, 485-496. 